\title{
Local Release of GABAergic Inhibition in the Motor Cortex Induces Immediate-Early Gene Expression in Indirect Pathway Neurons of the Striatum
}

\author{
Sabina Berretta, Hemai B. Parthasarathy, and Ann M. Graybiel \\ Department of Brain and Cognitive Sciences, Massachusetts Institute of Technology, Cambridge, Massachusetts 02139
}

The neocortex is thought to exert a powerful influence over the functions of the basal ganglia via its projection to the striatum. It is not known, however, whether corticostriatal effects are similar across different types of striatal projection neurons and interneurons or are unique for cells having different functions within striatal networks. To examine this question, we developed a method for focal synchronous activation of the primary motor cortex (MI) of freely moving rats by local release of GABAergic inhibition. With this method, we monitored cortically evoked activation of two immediate-early gene protein products, c-Fos and JunB, in phenotypically identified striatal neurons. We further studied the influence of glutamate receptor antagonists on the stimulated expression of c-Fos, JunB, FosB, and NGFI-A.

Local disinhibition of $\mathrm{Ml}$ elicited remarkably selective induction of c-Fos and JunB in enkephalinergic projection neurons. These indirect pathway neurons, through their projections to the globus pallidus, can inhibit thalamocortical motor circuits. The dynorphin- containing projection neurons of the direct pathway, with opposite effects on the thalamocortical circuits, showed very little induction of c-Fos or JunB. The gene response of striatal interneurons was also highly selective, affecting principally parvalbumin- and NADPH diaphorase-expressing interneurons. The glutamate NMDA receptor antagonist MK-801 strongly reduced the cortically evoked striatal gene expression in all cell types for each gene examined. Because the gene induction that we found followed known corticostriatal somatotopy, was dose-dependent, and was selectively sensitive to glutamate receptor antagonists, we suggest that the differential activation patterns reflect functional specialization of cortical inputs to the direct and indirect pathways of the basal ganglia and functional plasticity within these circuits.

Key words: immediate-early genes; neural plasticity; basal ganglia; striatum; motor cortex; corticostriatal; coherent activation; picrotoxin; GABA-A; enkephalin; dynorphin; rat
A broad range of experimental evidence implicates the basal ganglia in functions related to procedural learning, context-dependent motor control, and reward-related behavior (Apicella et al., 1992; Robbins and Everitt, 1992; Graybiel et al., 1994; Graybiel, 1995; Hikosaka et al., 1995; Houk et al., 1995; Schultz, 1995; Knowlton et al., 1996). These functions share the property of requiring both rapid and long-term plasticity of neural connections and synaptic efficacies. Electrophysiological and biochemical findings support the view that the glutamatergic cortico-basal ganglia pathways exhibit such plasticity. Both long-term depression (LTD) and long-term potentiation (LTP) have been demonstrated in the striatum after cortical stimulation (for review, see Calabresi et al., 1996). Immediate-early genes, considered potential indicators of neuronal activity capable of producing long-term alterations in neuronal properties, also have been shown to be induced in the striatum after both pharmacological manipulation of glutamate and electrical stimulation of the cortex (Fu and Beckstead, 1992; Wan et al., 1992; Parthasarathy et al., 1997; for reviews, see Hughes and Dragunow, 1995; Morgan and Curran, 1995).

It is not yet clear how plasticity in the cortico-basal ganglia

Received Dec. 10, 1996; revised Feb. 26, 1997; accepted March 26, 1997.

This work was supported by National Institutes of Health Javits Award 5 R01NS25529, the National Parkinson Foundation, and the Stanley Foundation. We thank Dr. Lidia Mayner, Diane Major, Glenn Holm, and Zohar Sachs for their help, and Henry Hall, who is responsible for the photography. We also thank Dr. R. Bravo for his gift of JunB and NGFI-A antisera and Dr. S. Watson for his gift of leumorphin antiserum.

Correspondence should be addressed to Dr. Ann M. Graybiel, Walter A. Rosenblith Professor, Department of Brain and Cognitive Sciences, Massachusetts Institute of Technology, E25-618, Cambridge, MA 02139.

Copyright (C) 1997 Society for Neuroscience $0270-6474 / 97 / 174752-12 \$ 05.00 / 0$ system relates to the functional organization of the largest nucleus of this system, the corpus striatum. Nearly all regions of the neocortex project to the striatum. They are thought to activate, via glutamatergic synapses, direct pathway projection neurons that release the motor thalamus and brainstem and indirect pathway projection neurons that indirectly control the release functions of the direct pathway. In an admittedly oversimplified scheme, these opposing pathways are believed to control motor and cognitive/ affective behaviors as a push-pull system (Albin et al., 1989; Alexander and Crutcher, 1990). The neocortex also acts on different types of striatal interneurons that generate local feed forward and feedback networks within the striatum (Kawaguchi et al., 1995). Very little is yet known about how the cortex affects the distinct types of neurons in the striatum to contribute to the observed functional plasticity of the basal ganglia.

To approach this issue, we focally induced synchronized activity in the motor cortex in freely moving rats by local epidural application of the $\mathrm{GABA}_{\mathrm{A}}$ receptor antagonist picrotoxin. Picrotoxin effectively suppresses the effects of cortical inhibitory GABAergic interneurons (Connors et al., 1988), which strongly modulate excitatory drive from the neocortex (Connors, 1984; ChagnacAmitai and Connors, 1989a,b; Thomson and Deuchars, 1994). We then used this method in combination with dual-antigen immunohistochemistry to study the effects of such cortical stimulation on activation of a range of immediate-early genes in populations of phenotypically identified striatal neurons.

Our findings demonstrate that cortical activation modulates immediate-early gene expression in highly specific subpopulations of striatal neurons. Furthermore, the profile of genes targeted by 
Table 1. Quantification of double-labeling experiments

\begin{tabular}{llllcl} 
Cellular marker & $n$ & $\begin{array}{l}\text { c-Fos } \\
\text { (nuclei/section) }\end{array}$ & $\begin{array}{l}\text { c-Fos } \\
\text { (\%of c-Fos-positive cells } \\
\text { double-labeled for marker) }\end{array}$ & $\begin{array}{l}\text { JunB } \\
\text { (nuclei/section) }\end{array}$ & $\begin{array}{l}\text { JunB } \\
\text { (\% of JunB-positive cells } \\
\text { double-labeled for marker) }\end{array}$ \\
\hline Enkephalin & 6 & $139.2 \pm 62.7$ & $76.6 \pm 4.8$ & $363.3 \pm 124.8$ & $85.8 \pm 4.2$ \\
Dynorphin & 6 & $13.0 \pm 2.2$ & $7.2 \pm 2.7$ & $23.6 \pm 6.0$ & $5.1 \pm 1.0$ \\
Parvalbumin & 8 & $99.6 \pm 17.7$ & $22.2 \pm 1.8$ & $9.8 \pm 2.9$ & $0.7 \pm 0.1$ \\
NADPH diaphorase & 8 & $35.6 \pm 3.0$ & $3.9 \pm 0.02$ & $32.0 \pm 4.3$ & $1.4 \pm 0.1$ \\
ChAT & 8 & 0.0 & & 0.0 &
\end{tabular}

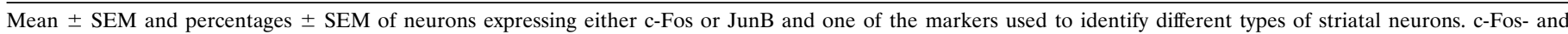

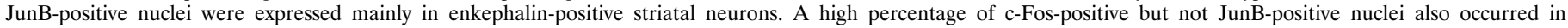
parvalbumin-containing interneurons.

the same cortical activity is distinct for individual striatal subpopulations. Finally, we have observed a spatial ordering of this specific and differential induction that may reflect cortical influence on plasticity within intrinsic striatal networks.

\section{MATERIALS AND METHODS}

Surgical procedure and picrotoxin application. Before surgery, rats were anesthetized with $50 \mathrm{mg} / \mathrm{kg}$ ketamine and $10 \mathrm{mg} / \mathrm{kg}$ xylazine and were placed in a Kopf stereotaxic device. In three rats, the frontal cortex was exposed by craniotomy, and the motor cortex was mapped by conventional microstimulation with monopolar tungsten electrodes to determine sites for picrotoxin application. Movements elicited with 40-200 $\mu \mathrm{A}$ current were noted for each electrode penetration and were used for orientation in relation to published maps of the rat's motor cortex (Neafsey et al., 1986). In the remaining rats $(n=112)$, the composite coordinates for the motor cortex were used to place a chronic well over the dura mater covering the motor cortex. A 2-mm-diameter bone flap, centered at A0.5, L1.5 from bregma (Paxinos and Watson, 1986), was first removed. Without opening the dura mater, a small plastic well with a $150 \mu \mathrm{l}$ capacity and an adjustable cap was fitted around the skull opening with dental cement and filled with $0.9 \%$ saline. The wound was sutured shut around the well. The rats were allowed to recover for $1 \mathrm{~d}$; then each rat was gently handheld while the $0.9 \%$ saline solution was removed and $300 \mu \mathrm{M}$ picrotoxin (or $0.9 \%$ saline in control rats) was injected into the well, and the well was recapped.

The rats were allowed free movement in their home cages for $2 \mathrm{hr}$ after application of picrotoxin. During this drug exposure period, all animals were observed closely, and any repetitive movements that were elicited were noted. In early experiments, picrotoxin was applied in doses ranging from $5 \mu \mathrm{M}$ to $300 \mu \mathrm{M}(n=3$ for each dose) to generate a dose-response curve relating the concentration of picrotoxin applied to the elicitation of movements and gene induction. In some experiments, a glutamate receptor antagonist (MK-801 or GYKI 52466) was injected intraperitoneally 30 min before application of picrotoxin $(300 \mu \mathrm{M})$ or saline. At the end of the $2 \mathrm{hr}$ survival time, the rats were anesthetized with an overdose of Nembutal $(150 \mathrm{mg} / \mathrm{kg})$ and perfused transcardially with $4 \%$ paraformaldehyde in $0.1 \mathrm{~m}$ sodium cacodylate buffer, $\mathrm{pH}$. 7.4.

A series of control experiments were performed. In five rats, saline was applied to the motor cortex to control for the effects of surgery and handling. In 10 rats ( 2 per group) the survival time was varied from 1 to $8 \mathrm{hr}$. In 12 rats, saline was applied to the motor cortex $30 \mathrm{~min}$ after intraperitoneal administration of either MK-801 or GYKI 52466 to control for the effects of these drugs on the gene induction monitored. In groups of five rats each, the vehicle for MK-801 (saline) or GYKI 52466 (CREMOPHOR EL plus saline) was injected intraperitoneally $30 \mathrm{~min}$ before picrotoxin application to control for possible effects of the vehicles. In six rats, the location of the well was shifted rostrally or caudally as a control for possible spread of picrotoxin to these neighboring regions of the neocortex. In two rats, deoxy-D-glucose, $2-\left[{ }^{14} \mathrm{C}(\mathrm{U})\right](2-\mathrm{DG} ; 25 \mu \mathrm{Ci}$ in $0.5 \mathrm{ml}$ ) was injected intraperitoneally $30 \mathrm{~min}$ after application of picrotoxin to monitor the spread of cortical activation by 2-DG autoradiography (Melzer et al., 1985). To control for possible effects of diffusion of picrotoxin into the striatum, in three rats $300 \mu \mathrm{M}$ picrotoxin was injected intrastriatally through an indwelling cannula. Finally, in one rat in which the cortex immediately underlying the well suffered hemorrhagic damage, we examined the brain for possible effects of picrotoxin acting on cortex outside the application site.

Drugs. Picrotoxin, purchased from Sigma (St. Louis, MO), was dis- solved in hot saline; during the experiment it was kept at $37^{\circ} \mathrm{C}$. MK-801 and GYKI 52466 were purchased from RBI (Natick, MA). MK-801 (1 $\mathrm{mg} / \mathrm{kg}$ ), a noncompetitive NMDA receptor antagonist (Wong et al., 1986), was dissolved in saline; GYKI $52466(10 \mathrm{mg} / \mathrm{kg})$, a highly selective noncompetitive AMPA/kainate receptor antagonist (Donevan and Rogawski, 1993), was dissolved in CREMOPHOR EL (Sigma) and then diluted in saline (20\% CREMOPHOR EL in the final solution).

Immunohistochemistry. Brains were removed, post-fixed for $\sim 1 \mathrm{hr}$, placed in a $0.1 \mathrm{M}$ cacodylate-buffered solution with $20 \%$ glycerol for a minimum of $12 \mathrm{hr}$, and cut into 15 or $30 \mu \mathrm{m}$ coronal sections on a sliding microtome. Free-floating sections were later processed for immunohistochemistry with polyclonal antisera raised against c-Fos (Oncogene Science Ab-2; 1:200 and 1:500), FosB (Santa Cruz Biotechnology, Santa Cruz, CA; 1:6000), c-Jun (Oncogene Science Ab-1; 1:500), JunB (gift from Dr. R. Bravo; 1:12000), NGFI-A (gift from Dr. R. Bravo; 1:10,000), ChAT (Incstar, Stillwater, MN; 1:2000), parvalbumin (Sigma; 1:1000), met-enkephalin (Incstar; 1:1000), or dynorphin (leumorphine; gift from Dr. S. Watson; $1: 20,000 \mathrm{~K})$. Sections were treated consecutively with $10 \%$ methanol and $3 \%$ hydrogen peroxide to inhibit endogenous peroxidase, and $5 \%$ normal goat serum, followed by overnight incubation at $4{ }^{\circ} \mathrm{C}$ in primary antiserum in $0.01 \mathrm{M} \mathrm{Na}^{+}-\mathrm{K}^{+}$PBS containing $0.2 \%$ Triton $\mathrm{X}-100$ (PBS-Tx). After incubation with biotinylated secondary antiserum, sections were processed with avidin-biotin kits (Vector Laboratories, Burlingame, CA) and developed with nickel-enhanced diaminobenzidine $\left(0.02 \%\right.$ DAB, $0.08 \%$ nickel ammonium sulfate) containing $0.002 \% \mathrm{H}_{2} \mathrm{O}_{2}$.

Dual-antigen immunohistochemistry (Berretta et al., 1992; Hiroi and Graybiel, 1996) was performed on 15- $\mu$ m-thick free-floating sections. For double-labeling of c-Fos or JunB and dynorphin, parvalbumin, or ChAT, two consecutive immunostainings were performed. For each, sections were incubated overnight in the primary antiserum, and the sections were then incubated in biotinylated secondary serum and in streptavidin. The first antigen was detected with nickel-enhanced DAB (purple-gray reaction product) and the second with cacodylate-buffered DAB (brown reaction product). Between the two procedures, the sections were washed overnight in PBS-Tx followed by blocking steps in $\mathrm{H}_{2} \mathrm{O}_{2}$, avidin, and biotin. Bovine serum albumin was substituted for normal secondary serum throughout. For double-labeling for c-Fos or JunB and enkephalin, a different protocol was used. c-Fos or JunB were immunolabeled as a dot-like black reaction product with an immunogold procedure, and the enkephalin was immunostained with cacodylate-buffered DAB. Sections were incubated overnight in primary antiserum against c-Fos or JunB, rinsed, and incubated overnight in Jansen gold-conjugated secondary antibody (1:50). After several rinses in 1\% sodium acetate, the goldconjugated secondary antiserum was detected by silver intensification (Intense-M silver intensification kit, Amersham, Arlington Heights, IL). Standard immunohistochemistry for enkephalin, with development in DAB-cacodylate or Vector VIP, followed. Rinses in Tris-phosphate buffer for c-Fos or JunB labeling, and in PBS buffer for enkephalin labeling, were performed after each step of the procedure. Triple immunostaining (see Fig. 5, inset) for c-Fos, parvalbumin, and enkephalin was obtained with three sequential immunohistochemistry procedures and developments with silver intensification, DAB-cacodylate, and Vector VIP, respectively.

Staining for NADPH diaphorase was performed histochemically by an NADPH/nitroblue tetrazolium reaction (Vincent, 1983) after immunohistochemistry.

Deoxyglucose experiments. 2-DG was acquired from DuPont NEN (Wilmington, DE), centrifuged under vacuum, and reconstituted with $0.9 \%$ saline. 
A

Figure 1. Focal epidural application of picrotoxin onto the MI through a chronically implanted, well induced c-Fos expression and increased metabolic activity in the underlying cortex and in the dorsolateral caudoputamen. $A$, An example of the microstimulation maps of MI on which stereotaxic coordinates for the implanted wells were based. The area in gray represents the size and the position of the well. $F$, Foot; $V$, vibrissae; $E$, elbow; $W$, wrist; $T$, trunk; $N$, neck; $H$, hand; $D 5 F$, digit $5 ; X$, no response. Coordinates relative to bregma. $B$, Schematic representation (anterior $=9.7$; Paxinos and Watson, 1986) of the most intense c-Fos induction observed in the cortex after picrotoxin application ( gray) superimposed on points at which microstimulation elicited movements of the elbow $(E)$ and of the elbow and vibrissae $(E / V)$ at the same position in a different experiment. $C$, Serial transverse sections through the caudoputamen illustrating the longitudinally extended dorsolateral induction of c-Fos in the striatum after picrotoxin application to the motor cortex. Scale bar, $500 \mu \mathrm{m}$.

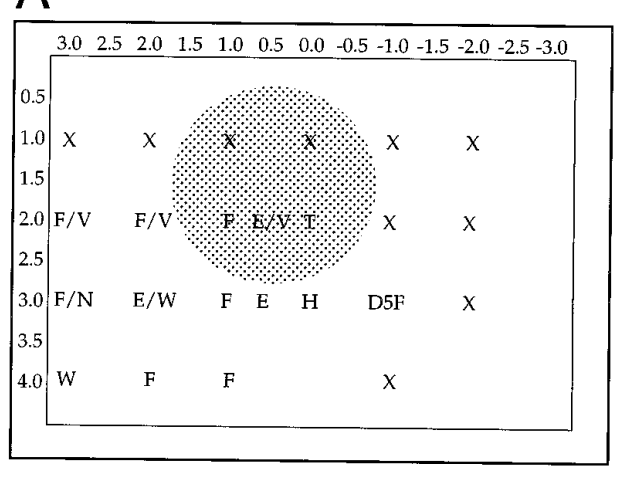

$\mathrm{B}$
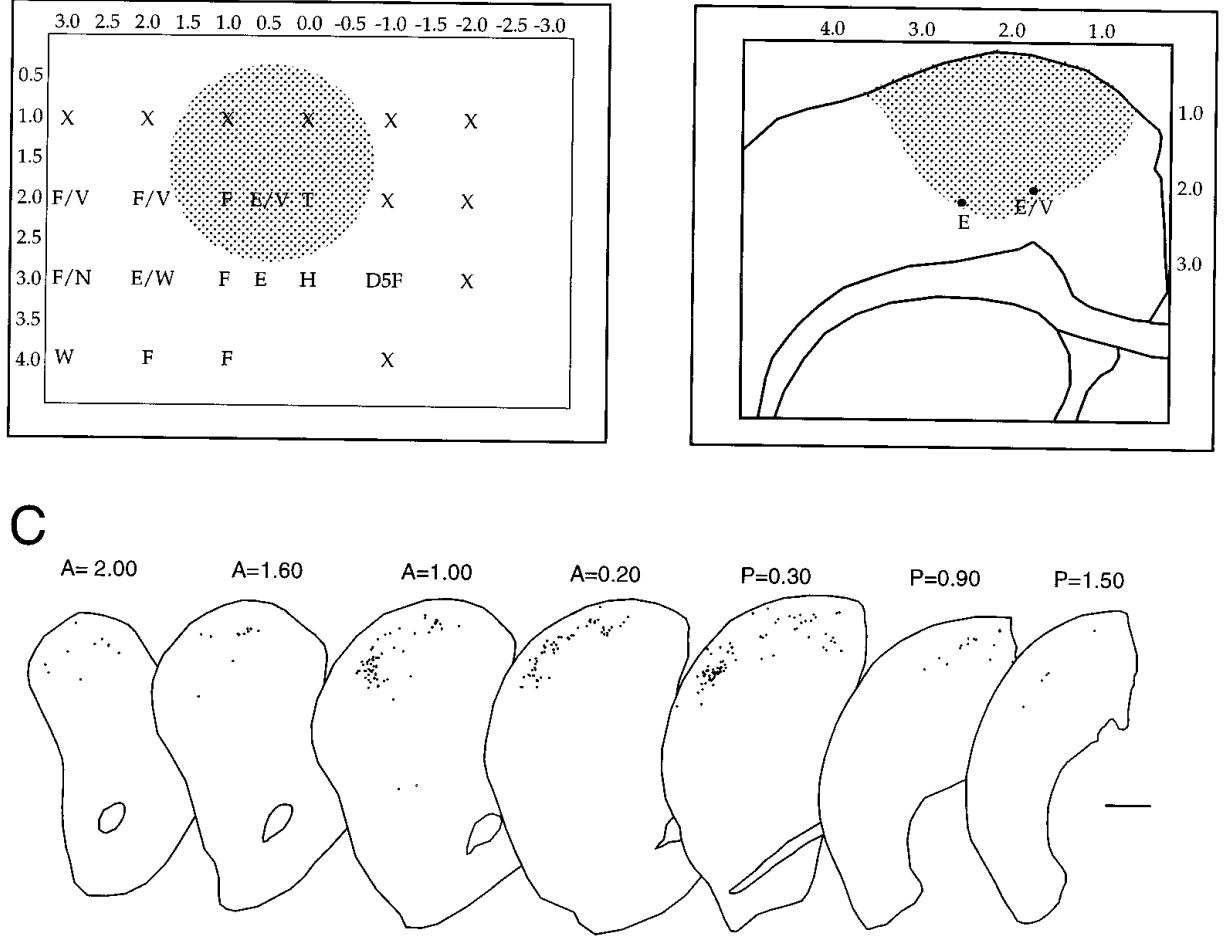

Thirty minutes after application of picrotoxin, $0.5 \mathrm{ml}$ of 2-DG $(25 \mu \mathrm{Ci})$ was injected intraperitoneally. The rats were perfused $45 \mathrm{~min}$ later $(1 \mathrm{hr}$ and 15 min total survival time), and their brains were removed, frozen, and cut on a cryostat into $20-\mu \mathrm{m}$-thick sections. The slides were exposed to Kodak BioMax MR film for 1 week and then developed in Kodak GBX.

Estimates of numbers of neurons expressing each transcription factor immunoreactivity. For each transcription factor studied (c-Fos, FosB, NGFI-A, JunB, c-Jun), representative sections from sample cases treated with saline on the motor cortex $(n=5), 300 \mu \mathrm{M}$ picrotoxin $(n=10), 300$ $\mu \mathrm{M}$ picrotoxin plus $1 \mathrm{mg} / \mathrm{kg}$ MK-801 $(n=10), 300 \mu \mathrm{M}$ picrotoxin plus 10 $\mathrm{mg} / \mathrm{kg}$ GYKI $52466(n=10), 300 \mu \mathrm{M}$ picrotoxin plus vehicle for MK-801 $(n=5)$, and $300 \mu \mathrm{M}$ plus vehicle for GYKI $52466(n=5)$ were selected and immunostained at the same time. For the analysis of data, a computerized imaging system (Biocom, Les Ulis, France) was used. For each protein, a section from a representative case was chosen as a reference standard to establish threshold conditions. The contrast and luminosity were adjusted by eye so that only darkly stained nuclei would be counted. Then, for each brain, the two sections that showed the most intense induction were selected, and the number of nuclei with immunostaining above the threshold level was counted. Kruskal-Wallis testing followed by comparisons of treatment and control conditions and ANOVA analysis followed by Scheffé post hoc testing were performed to evaluate the significance of differences among treatments.

Estimates of gene induction in different striatal cell types. We performed two types of analysis: one to establish which striatal neuron subtypes were induced to express the transcription factors c-Fos and/or JunB after application of picrotoxin on the motor cortex, and a second to study possible differences in the striatal subtypes affected when MK-801 or GYKI 52466 was given before picrotoxin application.

To mark striatal projection neurons, we immunostained for enkephalin and dynorphin, phenotypic markers of indirect and direct pathway projection neurons, respectively (Graybiel, 1990; Gerfen, 1992). To estimate the relative levels of gene induction in these two types of neuron, we chose in each case the doubly immunostained sections in which either c-Fos or JunB immunoreactivity was most intense and counted neurons that expressed c-Fos or JunB alone without enkephalin or dynorphin and neurons that expressed one of these transcription factors and either enkephalin or dynorphin. In some cases neurons labeled for enkephalin or dynorphin but not immunopositive for c-Fos or JunB were also counted.

To estimate the degree of gene induction in striatal interneurons, we analyzed sections double-labeled with c-Fos or JunB and with one of the following markers for striatal interneurons: choline acetyl transferase (ChAT) to mark the cholinergic interneurons, parvalbumin to mark the GABAergic interneurons expressing parvalbumin, and NADPH diaphorase to mark interneurons containing nitric oxide synthase, neuropeptide $\mathrm{Y}$, and somatostatin. For counting we chose the sections that showed the highest induction of c-Fos or JunB and then outlined the region of the caudoputamen that showed induction. Inside this region, for sections immunostained for each interneuronal cell type, we counted neurons that only showed labeling with the interneuronal marker and neurons that were labeled both for the interneuronal marker and c-Fos or JunB. In some cases, to obtain a comparison between the distribution of doubly labeled nuclei and the full field of gene induction, nuclei labeled with c-Fos or JunB only were counted as well. For comparisons among the groups treated with $300 \mu \mathrm{M}$ picrotoxin and those pretreated with glutamate antagonists, the results were evaluated by Kruskal-Wallis testing followed by comparisons of treatments and controls and ANOVA testing followed by post hoc testing (Scheffé).

\section{RESULTS}

\section{Application of picrotoxin to the motor cortex evokes discrete movements and localized gene induction in the neocortex and striatum}

To study the effects of cortical activity on striatal immediate-early gene expression in awake, freely moving animals, we preimplanted wells over focal craniotomies, without disturbing the dura mater overlying the region of interest to minimize trauma to the cortex. To determine the optimal location for the wells, we mapped MI with electrical stimulation in three rats (Fig. 1A,B). On the basis of these maps and of those of Neafsey and coworkers (1986), we chose standard coordinates estimated to correspond to the limb region of the MI map except for a slightly medial bias imposed to favor well stability (Fig. $1 B$ ).

Approximately $15 \mathrm{~min}$ after the addition of $300 \mu \mathrm{M}$ picrotoxin to the implanted wells, rats began to exhibit localized motor tics involving either the forelimb or hindlimb or both and lasting several tens of milliseconds. The tics had a frequency of $\sim 26 / \mathrm{min}$ 

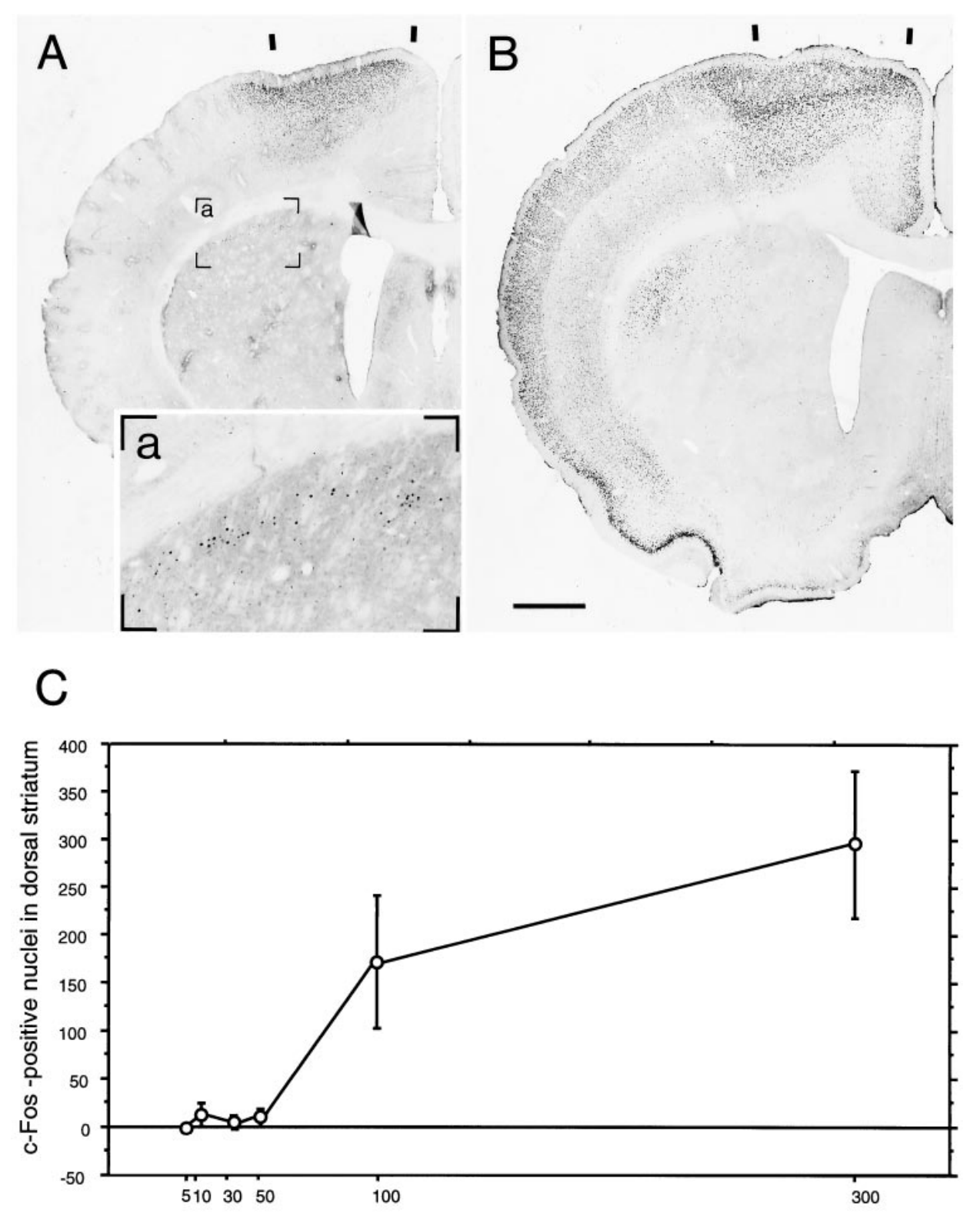

Figure 2. Focal epidural application of picrotoxin induces c-Fos expression in a concentration-dependent manner. $A, B$, Photomicrographs of sections immunostained for $\mathrm{c}$-Fos from experiments in which $75 \mu \mathrm{M}(A)$ or $300 \mu \mathrm{M}(B)$ picrotoxin was applied to MI. A wedge-shaped area of intense c-Fos induction, corresponding to the site of picrotoxin application, is detectable. In both cases, c-Fos induction in the striatum is restricted to the dorsolateral caudoputamen. The inset $(a)$ shows bracketed region at higher magnification. Markers above the overlying cortex indicate the approximate location of the well. $C$, Relationship between the number of immunodetectable c-Fos-positive nuclei in the ipsilateral caudoputamen and the concentration of picrotoxin applied to MI (mean \pm SEM;

Concentration in $\mu \mathrm{M}$ of picrotoxin applied to the motor cortex $N=18 ; n=3$ /group). Scale bar, $1 \mathrm{~mm}$.

( $\sim 2.3 \mathrm{sec}$ intervals). The tics did not interfere with the spontaneous behavior of the animals, which in most experiments spent periods of time sleeping, grooming, drinking, and feeding. The motor tics continued for the entire duration of the treatment $(2 \mathrm{hr}$ and $15 \mathrm{~min}$ ). The occurrence of such discrete tics was used as the criterion for further analysis. In five rats, the stimulation evoked motor tics that evolved into generalized seizures. These rats were excluded from the study. No behavioral response was seen in the saline-treated controls or in controls with other well sites.

Because different nuclear immediate-early genes are regulated differentially (for reviews, see Sheng and Greenberg, 1990; Hughes and Dragunow, 1995), we studied the expression of four of them, c-Fos, JunB, NGFI-A, and FosB, in an attempt to survey cortically induced gene activation in the striatum. Our attempts to evoke c-Jun expression were not successful. In every rat in which well defined motor tics were elicited, we found localized induction of all four transcription factor immunoreactivities in the motor cortex and the sensorimotor sector of the ipsilateral striatum (Fig. $2 A, B$ ). Induction in the striatum was first detectable $1 \mathrm{hr}$ after picrotoxin application and reached a maximum at $2 \mathrm{hr}$ (data not shown). In the neocortex, the epidural picrotoxin induced intense gene expression in a wedgeshaped zone, most sharply demarcated in sections stained for c-Fos (Figs. $1 B, 2 A, B$ ) and JunB (see Fig. 4A). Outside this intense focal zone, there was weaker induction in cortical neurons throughout the hemisphere (Figs. $2 A, 4 A$ ). This general pattern of a dense focus and a more diffuse extended activation zone was visible also in the neocortex of rats prepared for 2-DG autoradiography (Fig. 3A). Similarly, in the striatum, the dorsolateral zone of immediate-early gene activation was matched by a comparably situated region showing heightened metabolic activity in the case prepared for 2-DG autoradiography (Fig. 3B).

In the neocortex, for all four transcription factors, there was widespread induction in the supragranular and infragranular layers, whereas induction was weak or absent in layer 4. Details of the distribution patterns for the protein immunoreactivities differed. This was most obvious for JunB, which lacked the differentially strong 

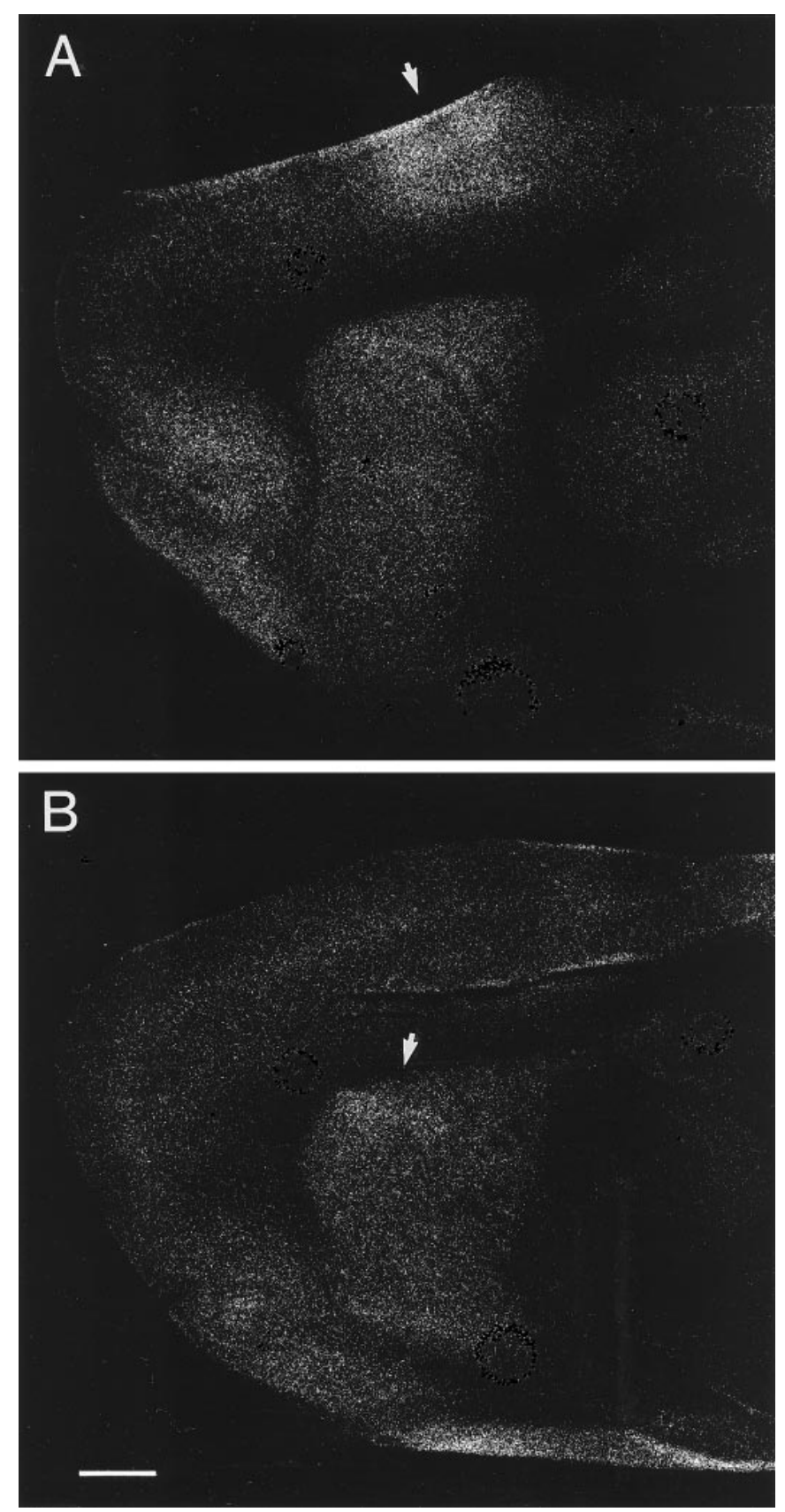

Figure 3. Autoradiograms of two parasagittal sections demonstrating the effects of picrotoxin application to MI on the uptake of $\left[{ }^{14} \mathrm{C}\right] 2-\mathrm{DG}$. In $A$, the arrowhead indicates a wedge-shaped region of high uptake approximating the site of picrotoxin application (lateral $=2.4$; Paxinos and Watson, 1986). In $B$, the arrowhead indicates the corresponding region of heightened labeling in the dorsolateral caudoputamen (lateral $=4.6$; Paxinos and Watson, 1986). Scale bar, $1 \mathrm{~mm}$.

induction in layers 3 and 5 shown by c-Fos, FosB, and NGFI-A immunoreactivities (Fig. 4A). We found little or no induction of any of the four protein classes in the contralateral neocortex.

No gene induction was seen in the saline-treated controls. Furthermore, in Nissl stains, we found no evidence of obvious cellular damage in the neocortex or in the underlying striatum after picrotoxin application (also see Collins and Olney, 1982). In control rats in which picrotoxin was applied over cortical regions other than the motor cortex, the induction of Fos-Jun proteins occurred in the
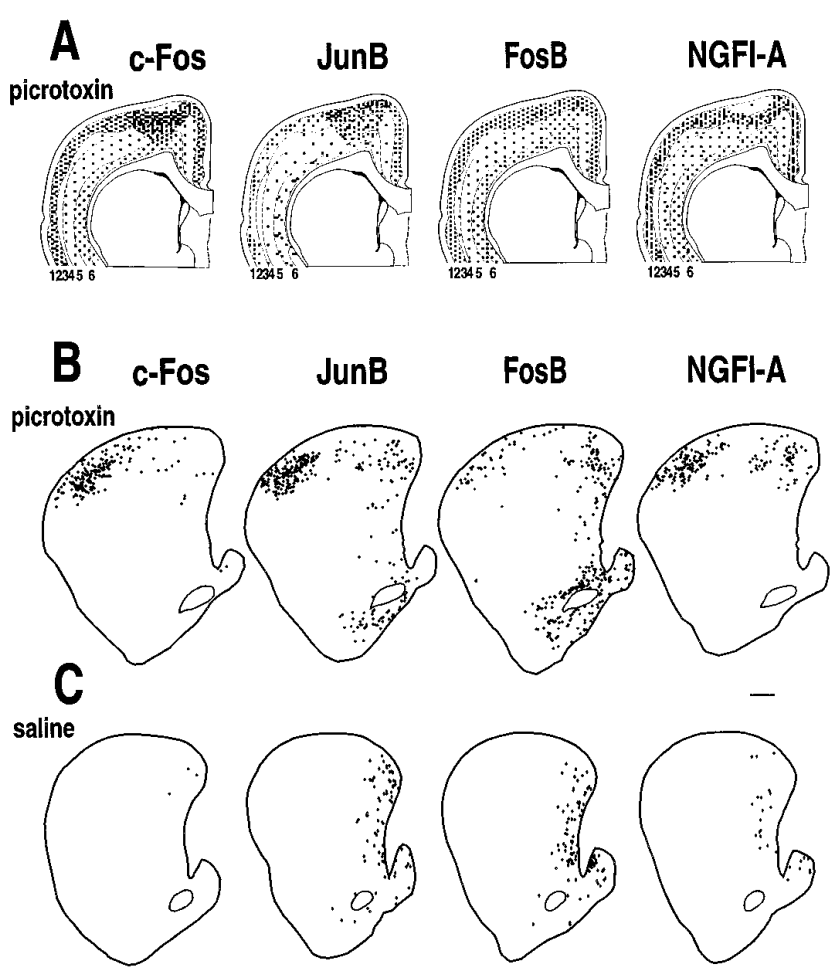

Figure 4. Picrotoxin-induced excitation of MI elicits different patterns of c-Fos, JunB, FosB, and NGFI-A induction in the cerebral cortex $(A)$ and striatum $(B)$. Immediate-early gene induction in the striatum of salinetreated controls $(C)$ was found only along the medial edge of the caudoputamen. Scale bar, $500 \mu \mathrm{m}$.

absence of evoked movement with different distributions and intensities. The possibility that the striatal gene induction was produced by leakage of picrotoxin from the cortex to the striatum was excluded by the facts that the gene induction in the striatum was not directly underneath the site of application and that intrastriatal injections of picrotoxin $(n=3)$ did not lead to local expression of the genes. Finally, the one rat with a localized hemorrhage directly under the well did not show induction of the proteins in the striatum.

\section{Induction of c-Fos expression in the sensorimotor striatum by $\mathrm{MI}$ picrotoxin application is dose-dependent}

In 18 rats (3 rats/group), we performed a dose-effect study by applying concentrations of picrotoxin varying from 0 to $300 \mu \mathrm{M}$ to $\mathrm{MI}$ and subsequently counting the numbers of c-Fos-positive neurons in representative sections through the caudoputamen (Fig. 2C). We found an orderly dose-effect relationship with a threshold for induction at picrotoxin concentrations between $50 \mu \mathrm{M}$ (9.3 nuclei per section $\pm 16.2 \mathrm{SEM})$ and $100 \mu \mathrm{M}(171.0$ nuclei per section \pm 69.0 SEM). Strong induction (500 nuclei per section \pm 184.8 SEM) was found almost invariably at $300 \mu \mathrm{M}$. At this dose, which was used for all subsequent experiments, there was a consistent, somatotopically localized behavioral response to the picrotoxin and a consistent core of intense c-Fos induction in the sensorimotor zone accompanied by a margin of weaker induction.

\section{Stimulation of the motor cortex induces immediate- early genes in a topographically ordered pattern in the striatum}

Each of the four transcription factors showed a main zone of induction in the dorsolateral caudoputamen (Figs. $2 \mathrm{~A}, 4 \mathrm{~B}$ ) in the region 
corresponding to the sensorimotor sector, which receives direct input from MI (McGeorge and Faull, 1989). Within the principal zone of induction, the activation of gene expression was ordered in a roughly topographic manner, judging from the movement elicited during stimulation. In rats with hindlimb motor tics, the fields of induction were generally dorsomedial to those in rats with forelimb motor tics. In cases in which the location of the well was shifted rostrally or caudally with respect to the standard site $(n=6)$, gene induction in the striatum occurred with different distributions.

The results for two forelimb cases are shown in Figures $1 C$ and $4 B$. The zones of induction were elongated anteroposteriorly (Fig. $1 C$ ). At some levels, especially posteriorly, immunopositive nuclei tended to form clusters. Anteriorly, the distribution of labeled nuclei was more diffuse. Immunostaining for c-Fos, JunB, FosB, and NGFI-A showed roughly comparable major zones of induction (Fig. $4 B$ ), but the levels of induction in the sensorimotor striatum in any given animal were generally stronger for JunB and NGFI-A than for c-Fos, and they were least for FosB (Fig. 3B). FosB was also exceptional in showing considerable induction in the ventral foot of the caudoputamen and adjoining nucleus accumbens (Fig. 4B). As judged by comparisons with expression levels in saline-treated controls (Fig. $4 C$ ), picrotoxin induced only weak striatal expression of the other protein species outside the dorsolateral zone.

We consistently found weak induction of c-Fos and JunB in the sensorimotor sector of the contralateral caudoputamen in a roughly mirror-image position to the main ipsilateral field. Because of the higher levels of basal expression of NGFI-A and FosB, such low levels of induction, if present, would have been virtually impossible to detect.

\section{Stimulation of the motor cortex with picrotoxin selectively activates subclasses of striatal projection neurons and interneurons}

To identify the phenotypes of sriatal neurons activated by the cortical stimulation to express immediate-early genes, we used dual-antiserum immunohistochemistry with standard neurochemical markers for different classes of striatal neurons. The two main classes of striatal projection neurons coexpress different neuropeptides along with GABA. Most direct pathway neurons (and most neurons of striosomes, which project to the substantia nigra) express dynorphin. Most indirect pathway neurons express enkephalin (Graybiel, 1990; Gerfen, 1992). We therefore were able to identify these neurons as distinct classes. We also identified three classes of striatal interneurons with antiserum against parvalbumin to label the fast-spiking GABAergic interneurons, antiserum against ChAT to label the large aspiny cholinergic striatal interneurons, and enzyme histochemistry for NADPH diaphorase to detect the striatal interneurons that express this enzyme (putatively identified as nitric oxide synthase) along with neuropeptide Y and somatostatin (Kawaguchi et al., 1995; FigueredoCardenas et al., 1996). We restricted the analysis to doublelabeling for c-Fos and JunB because of their relatively low levels of constitutive expression in the striatum.

We found remarkable selectivity in the patterns of gene induction in both the projection neurons and the interneurons (Figs. 5, 6; Table 1). Projection neurons make up $>90-95 \%$ of all neurons in the rat striatum and are equally divided into dynorphin-containing (direct pathway) and enkephalin-containing (indirect pathway) types. After the MI stimulation, fully $70-80 \%$ of all the striatal neurons expressing c-Fos were enkephalin-containing neurons (Fig. 5B, Table 1). Within the region of most intense induction, 35-40\% of enkephalinpositive neurons expressed c-Fos. Only $7 \%$ of c-Fos-positive neurons expressed dynorphin (Figs. $5 A, 6 A$; Table 1 ). Thus nearly all of the striatal projection neurons activated by cortical stimulation to express c-Fos-like protein were neurons of the indirect pathway. These double-labeled projection neurons were concentrated in the region of densest c-Fos induction, and the small numbers of dynorphincontaining neurons excited to express c-Fos-like protein were always found near the center of this region (Fig. $6 A$ ).

Nearly all the remaining c-Fos-positive neurons were parvalbumin-containing interneurons (Figs. $5 C, 6 A$; Table 1). Up to $22 \%$ of c-Fos-positive nuclei were in parvalbumin-positive neurons, a remarkably high percentage given that the parvalbumin-containing neurons are thought to make up only $3-5 \%$ of all neurons in the rat's caudoputamen (Kawaguchi et al., 1995). The activated parvalbumin-positive neurons were distributed both within the dense core of the field of induction and in its periphery (Fig. 6A). To estimate how fully this interneuronal population was activated to express c-Fos immunoreactivity, we counted all the neurons immunostained for parvalbumin and all of those that in addition were c-Fos-positive. In the region of densest induction, the percentage of all parvalbumin-positive neurons that were c-Fos-labeled was $88 \pm 2.3 \mathrm{SEM}$. The percentage of parvalbumin-positive neurons that were c-Fos-positive was as high as $78 \pm 4.6 \mathrm{SEM}$ when the surrounding zone of less intense induction was also included.

Of the remaining c-Fos-positive neurons, 3-4\% expressed NADPH diaphorase and thus corresponded mainly to the somatostatin-containing neurons of the striatum (FigueredoCardenas et al., 1996) (Fig. 6A, Table 1). They had a clearly patterned distribution that was different from those of any other of the c-Fos-labeled neurons (Fig. 6 $A$ ), and they were least well represented in the central field of induction, increased in number in the more weakly labeled marginal zone around this field, and extended into a broad zone including much of the lateral part of the striatum unoccupied by other c-Fos-labeled cells. Within this entire region, the percentage of NADPH diaphorase-positive neurons that expressed c-Fos was $44 \pm 2.8 \mathrm{SEM}$. In the central region, this percentage dropped to $32 \pm 5.1 \mathrm{SEM}$. We found no ChAT-positive neurons double-labeled for c-Fos. We did not stain for calretinin, a marker for another class of striatal interneurons, but the labeling we did find must collectively have accounted for most striatal interneurons.

The induction of JunB-like protein by stimulation of MI was even more selective for enkephalin-containing projection neurons than that for c-Fos (Fig. 6B). Of all JunB-positive neurons, 85-90\% were immunoreactive for enkephalin (Figs. 5E, 6B; Table 1). Approximately $50 \%$ of the enkephalinergic neurons within the region of most intense induction were activated to express JunB. Only $4-6 \%$ of the JunB-positive neurons expressed dynorphin (Figs. 5D, 6B; Table 1). These few dynorphin-positive, JunB-positive neurons were distributed within the core of the field of induction. In contrast to c-Fos, JunB was not detectably activated in large numbers of striatal interneurons (Figs. $5 F, 6 B$; Table 1 ). Only $0.7 \%$ of JunB-positive nuclei were in parvalbumin-containing interneurons. These made up only $17 \pm 9 \%$ SEM of the parvalbumin-positive neurons within the total region of induction that expressed JunB. They were located mainly within the central field of induction. Approximately $1-2 \%$ of the entire JunB-positive population expressed NADPH diaphorase (Table 1). These neurons accounted for $\sim 29 \%$ of all NADPH diaphorase-containing cells and were widely scattered within the striatum (Fig. 6B). We found no ChAT-immunoreactive neurons that expressed JunB.

Taken together, these results suggest marked selectivity in the pattern of gene expression induced in the striatum in response to 

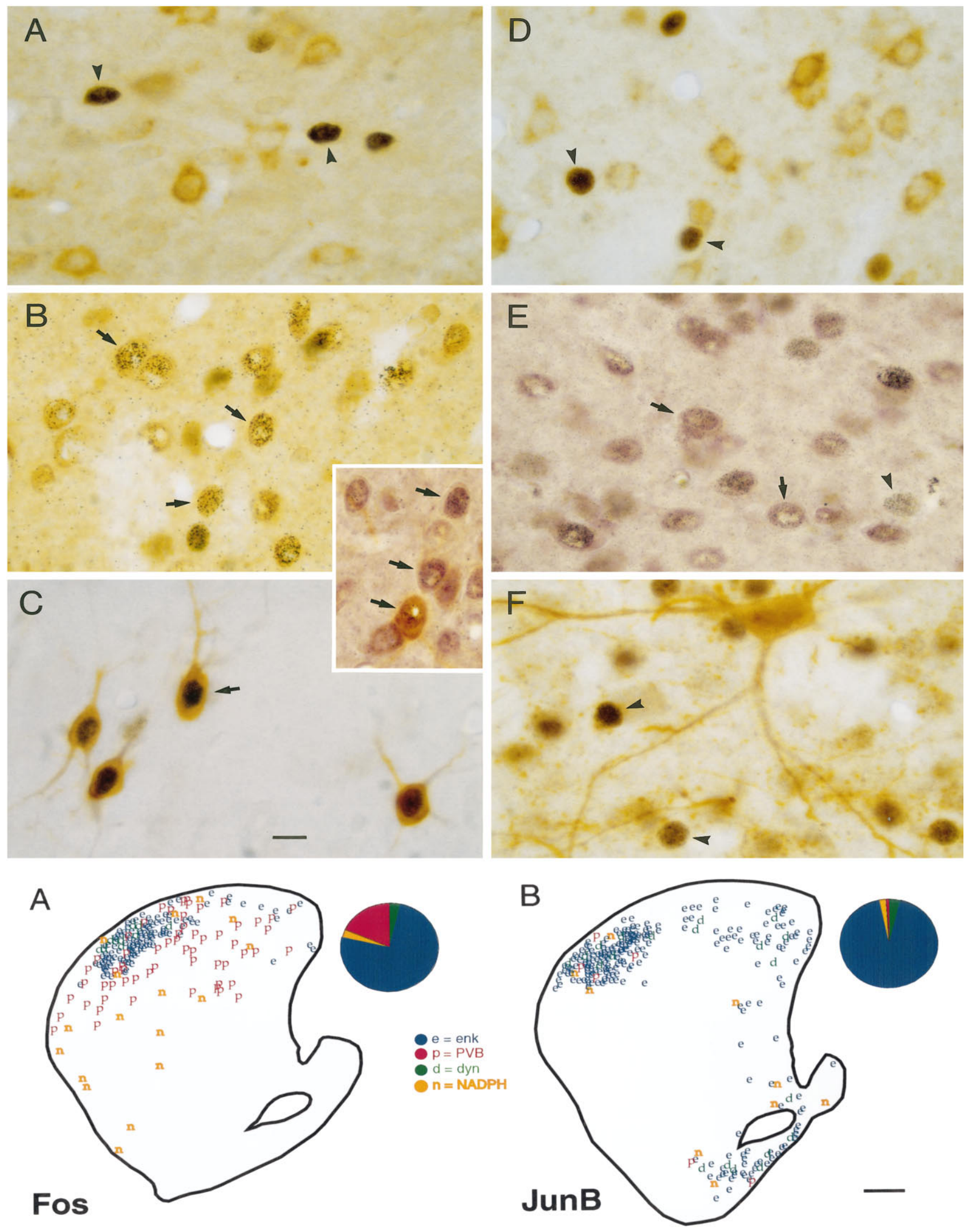
stimulation of the motor cortex, including coordinate and selective induction of c-Fos and JunB in enkephalinergic indirect pathway projection neurons and, for interneurons, selective induction of c-Fos in parvalbumin-containing and NADPH diaphorase-containing neurons.

\section{Cortically evoked expression of c-Fos and Jun expression in the striatum requires glutamate NMDA receptors and is modulated by glutamate AMPA/kainate receptors}

Corticostriatal fibers release glutamate or a closely related excitatory amino acid as neurotransmitter (Fonnum et al., 1981), and both NMDA and non-NMDA glutamate receptors are strongly expressed in the caudoputamen (Albin et al., 1992; Petralia and Wenthold, 1992; Tallaksen-Greene and Albin, 1994; Testa et al., 1994; Landwehrmeyer et al., 1995). To test for the relative requirements of these glutamate receptor subtypes in mediating the effects of cortical excitation on striatal gene induction, we combined the local epidural picrotoxin treatment with pretreatment with either a noncompetitive antagonist of the NMDA receptor, MK-801, or an AMPA/kainate receptor antagonist, GYKI 52466.

Injections of MK-801 ( $1 \mathrm{mg} / \mathrm{kg}, \mathrm{i} . \mathrm{p} ; n=6)$ and GYKI $52466(10$ $\mathrm{mg} / \mathrm{kg}$, i.p.; $n=6$ ) by themselves did not induce the expression of any of the transcription factor immunoreactivities we monitored nor did the vehicles for MK-801 (saline; $n=5$ ) or GYKI 52446 (CREMOPHOR EL plus saline; $n=5$ ) affect the levels of picrotoxin-induced gene expression when given as control pretreatments before the standard application of $300 \mu \mathrm{M}$ picrotoxin to the cortex (data not shown). Pretreatment with each antagonist, however, did affect the cortically induced gene expression observed in striatal neurons (Fig. 7).

Systemic injection of MK-801 reduced expression of each of the four protein classes in the striatum (Fig. 7A). The nonparametric Kruskal-Wallis test, followed by comparisons of treatment and control conditions, showed that MK-801 significantly $(p \leq 0.025)$ decreased cortically driven induction of c-Fos, JunB, NGFI-A, and FosB in the striatum. Testing with ANOVA followed by Scheffé post $h o c$ test showed significance only for c-Fos $(p<0.0001)$, probably because of the large variability within the groups.

In the cerebral cortex, the MK-801 completely abolished the induction of c-Fos in regions not directly under the picrotoxin well, so that only the activated wedge of induction remained (data not shown). The induction of JunB and NGFI-A in the cortex was also reduced but not completely abolished. Analysis of the phenotypes of the striatal neurons that still expressed c-Fos after MK-801 pretreatment showed that there was a comparable de- crease in each of the neuronal subclasses: no phenotype was particularly affected.

In contrast to MK-801, GYKI 52446 did not change the cortically driven striatal induction of c-Fos, NGFI-A, and FosB, and it increased the induction of JunB in the caudoputamen (ANOVA followed by Scheffé post hoc test, $p=0.009$; Kruskal-Wallis followed by comparisons of treatments vs control, $p \leq 0.025$ ) (Fig. $7 B$ ). As observed for MK-801, all striatal phenotypes showed a comparable response to the treatment with picrotoxin and GYKI 52466. Neither antagonist had a detectable effect on the motor tics evoked by the picrotoxin treatment.

\section{Picrotoxin-induced excitation of motor cortex induces gene expression in other subcortical sites}

We did a partial screening of cortically evoked gene induction in other subcortical regions of the forebrain, including other sites in basal ganglia circuitry and in the midbrain (Table 2).

For the thalamus, the results were surprising. There was little, if any, induction in the nucleus ventralis anterior-nucleus ventralis lateralis (VA-VL) complex, the main thalamic region interconnected with MI. By contrast, there was consistent induction of Fos-Jun proteins in neurons of the nucleus reticularis of the thalamus. In the center median (but not in the nucleus parafascicularis), there was activation of c-Fos but little activation of the other protein classes. This nucleus-specific pattern of activation is interesting given that each of these thalamic regions receives a direct projection from the stimulated MI.

In other nuclei of the basal ganglia circuit, the subthalamic nucleus, which receives a direct input from the MI, showed consistent induction of c-Fos and NGFI-A, as did the entopeduncular nucleus (internal pallidum) and the substantia nigra pars reticulata. There was more modest induction in the globus pallidus (external pallidum).

Of other regions analyzed, the amygdaloid complex (central and basolateral amygdaloid nuclei) showed marked activation, especially of c-Fos. The cortical stimulation also induced c-Fos, but not the other proteins, at immunodetectable levels in the pontine nuclei, which receive direct MI input. Altogether, c-Fos and NGFI-A showed the greatest responsivity across the structures analyzed.

\section{DISCUSSION}

Most theories of basal ganglia function maintain that the basal ganglia act mainly to process cortical inputs, subjecting them in the striatum to modulatory inputs from the midbrain and the thalamus and then forwarding the processed information to basal ganglia output targets via the antagonistic direct pathway-indirect

\footnotetext{
$\leftarrow$

Figure 5. Top. Stimulation of MI with picrotoxin elicits selective gene expression in striatal projection neurons and interneurons. Cortically driven c-Fos induction in the striatum was found very rarely in dynorphin-positive projection neurons $(A)$ but was intense in projection neurons expressing enkephalin $(B)$ and in parvalbumin-containing interneurons $(C)$. JunB was found even more rarely in dynorphin-expressing projection neurons $(D)$ but was strongly expressed in many enkephalin-positive projection neurons $(E)$. JunB was almost never induced in parvalbumin-containing interneurons $(F)$. Arrows indicate examples of doubly labeled neurons; arrowheads indicate examples of singly labeled nuclei. Double-immunolabeling for c-Fos or JunB (black) and dynorphin or parvalbumin (brown) was obtained by combining two different chromogens. In $B$ and $E$, c-Fos or JunB was labeled with a gold-conjugated antibody followed by silver intensification; enkephalin was labeled with DAB (brown) in $B$ and with Vector VIP (purple) in $E$. The inset shows an example of triple immunolabeling for c-Fos nuclei (black dot-like staining) expressed in enkephalin-positive neurons (purple) and in a parvalbumin-positive neuron (brown). Arrows indicate examples of double-labeling. Scale bar (shown in $C$ ): $10 \mu \mathrm{m}$ for all panels.

Figure 6. Bottom. Distribution of striatal neuron types expressing c-Fos and JunB and proportions of different types of striatal neuron expressing c-Fos and JunB. $A$, Most c-Fos-positive nuclei were expressed in enkephalinergic neurons and were clustered in a dorsolateral region of intense induction in the caudoputamen. Intermingled with them were small numbers of c-Fos-positive neurons that expressed dynorphin. Most of the remaining c-Fos-positive nuclei were contained in parvalbumin-positive neurons. These neurons were distributed within the region of most intense induction and also in a halo around it. NADPH diaphorase-positive neurons expressing c-Fos had an even wider field of distribution. $B$, A majority of JunB-positive nuclei were expressed in enkephalin-containing neurons concentrated in the dorsolateral caudoputamen. A few dynorphin-, parvalbumin-, and NADPH diaphorasecontaining neurons expressing JunB were present in the same region. Scale bar, $500 \mu \mathrm{m}$.
} 

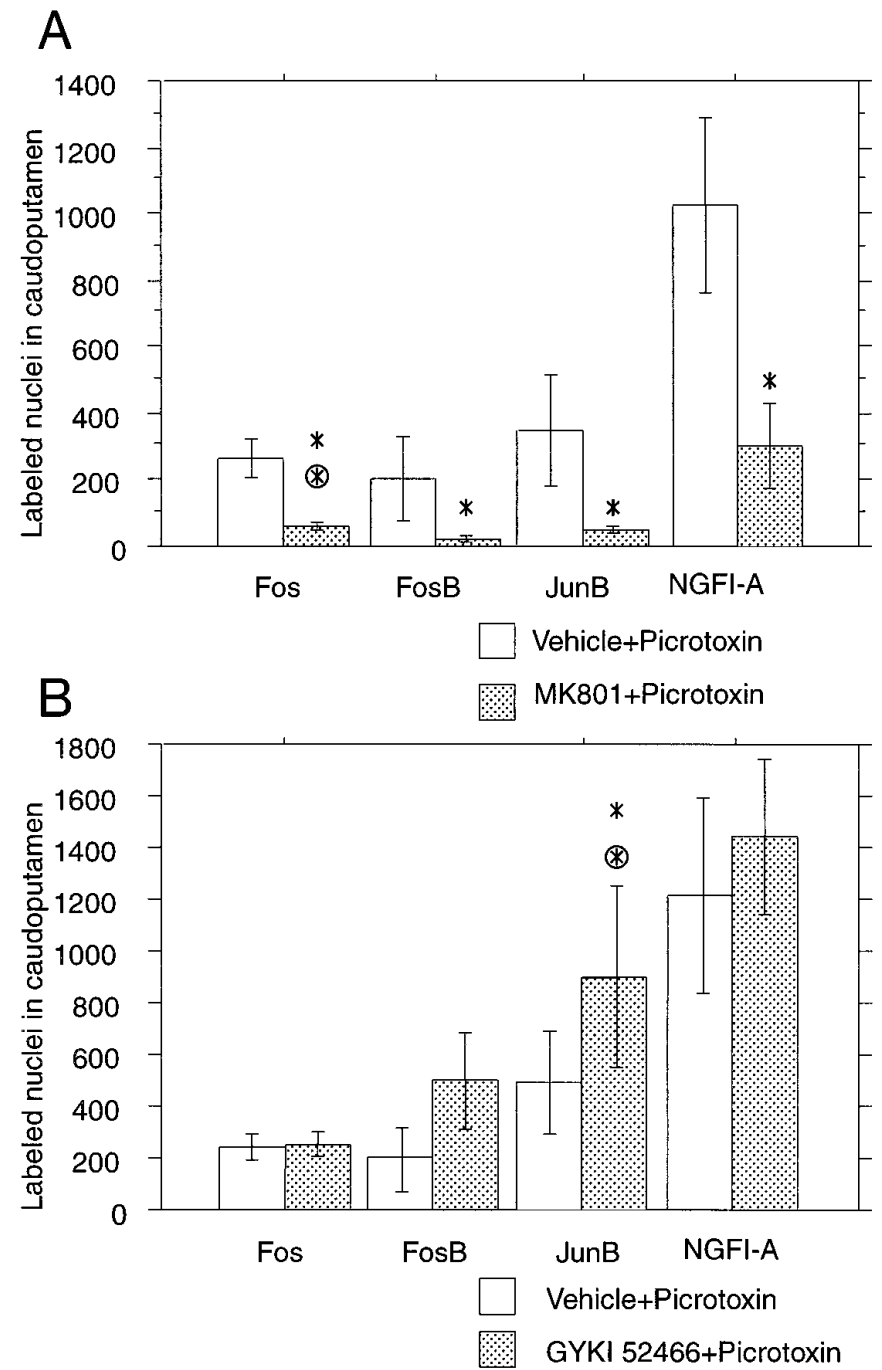

Figure 7. Effects of glutamate receptor antagonists on cortically driven gene expression in the striatum. $A$, The glutamate NMDA receptor antagonist MK-801 injected systemically before picrotoxin application $(n=10)$ significantly reduced picrotoxin-stimulated c-Fos, JunB, NGFI-A, and FosB induction in the caudoputamen relative to the levels of induction found in control rats that received vehicle injection before picrotoxin application $(n=10 ; p \leq$ 0.025). $B$, The glutamate AMPA receptor antagonist GYKI 52466 increased JunB induction in the caudoputamen but did not have detectable effects on c-Fos, NGFI-A, or FosB induction relative to control levels in rats treated with vehicle before picrotoxin $(n=10 ; p \leq 0.025)$. Asterisks indicate values significant by Kruskal-Wallis testing followed by comparisons of treatments versus control; circled asterisks indicate differences by ANOVA testing followed by Scheffé's post hoc test.

pathway control system. In these experiments, we studied the effects of repetitive cortical activity on the expression of transcription factors that are thought to be involved in neuronal plasticity in the basal ganglia. Our findings demonstrate sharp differences in the effects of cortical activation on different populations of striatal neurons. In particular, of the two classes of striatal projection neurons, it is neurons giving rise to the indirect pathway that express c-Fos and JunB in response to localized pharmacological excitation of MI. Dynorphin-containing direct pathway projection neurons are rarely affected. Moreover, parvalbumin-containing GABAergic interneurons respond to cortical excitation with increased expression of c-Fos but not JunB, and they do so in a wider striatal territory that is inclusive of the projection neurons.
Table 2. Estimated intensity of induction of c-Fos, JunB, NGFI-A, and FosB proteins after picrotoxin-induced activation of the motor cortex

\begin{tabular}{lllll} 
Structures & c-Fos & JunB & NGFI-A & FosB \\
\hline Caudoputamen & +++ & +++ & ++++ & ++++ \\
Neocortex & ++++ & +++ & ++++ & +++ \\
Nucleus accumbens & + & + & - & ++ \\
Globus pallidus & + & + & + & - \\
Entopeduncular nucleus & ++ & - & ++ & - \\
Substantia nigra & ++ & - & ++ & - \\
Subthalamic nucleus & +++ & - & ++ & - \\
Thalamus & & & & \\
$\quad$ VA-VL & - & - & - & - \\
$\quad$ Reticular nucleus & +++ & + & +++ & ++ \\
\multicolumn{1}{c}{ Amygdala } & ++ & ++ & + & +
\end{tabular}

In the thalamus, consistent activation occurred in the nucleus reticularis but not in the nucleus ventralis anterior-nucleus ventralis lateralis (VA-VL). c-Fos and NFGI-A, but not JunB and FosB, were induced in the entopeduncular nucleus (internal pallidum), substantia nigra, and subthalamic nucleus.

Finally, in this paradigm, there is a widespread induction of c-Fos and JunB in NADPH diaphorase-containing, putatively GABAergic interneurons, peripheral to the somatotopically defined focus of gene induction in the dorsolateral striatum. These differential corticostriatal activation patterns could reflect functional specializations in cortical control over the major output pathways of the basal ganglia and the interneuronal networks that modulate them.

\section{Effects of MI picrotoxin application on striatal neurons}

Because medium spiny striatal neurons receive numerous but only weakly effective synaptic inputs and are dominated by an inward rectifier that shunts depolarization, coherent cortical excitation is required to induce their firing (Wilson, 1995). We attempted to produce locally coherent activation by releasing a small region of MI from the inhibitory network of GABAergic interneurons that controls the spread of cortical excitation (Chagnac-Amitai and Connors, 1989a; Jacobs and Donoghue, 1991; Thomson and Deuchars, 1994). By using picrotoxin to lift cortical inhibition locally, rather than electrical stimulation to excite local regions, we avoided choosing an arbitrary pattern of cortical activity. We also avoided the activation of fibers of passage within the cortical region of interest. The observed well localized motor tics evoked by picrotoxin treatment and the subsequent clearly demarcated local regions of intense gene induction and 2-DG activation at the site of picrotoxin application and in the sensorimotor sector of the striatum are consistent with effects evoked from a discrete region of the motor cortex. We cannot directly relate, however, the gene induction patterns to specific patterns of neuronal firing in the striatum. Indeed, our results show that the selectivity of the gene induction for different classes of striatal neurons differs for different genes, as does the sensitivity of the induction to pretreatment with glutamate antagonists.

\section{NMDA receptor antagonists reduce, but AMPA/kainate receptor antagonists enhance, cortically evoked gene expression in the striatum}

Membrane depolarization of striatal neurons is known to be mediated by both NMDA and non-NMDA glutamate receptors (Kita, 1996, and references therein). Our experiments with MK-801 clearly implicate glutamate NMDA receptors in the cortically driven immediate-early gene induction in striatal neurons. Thus activation of NMDA receptors by corticostriatal fibers may have increased intracellular $\mathrm{Ca}^{2+}$ in the responsive striatal neurons, triggering the 

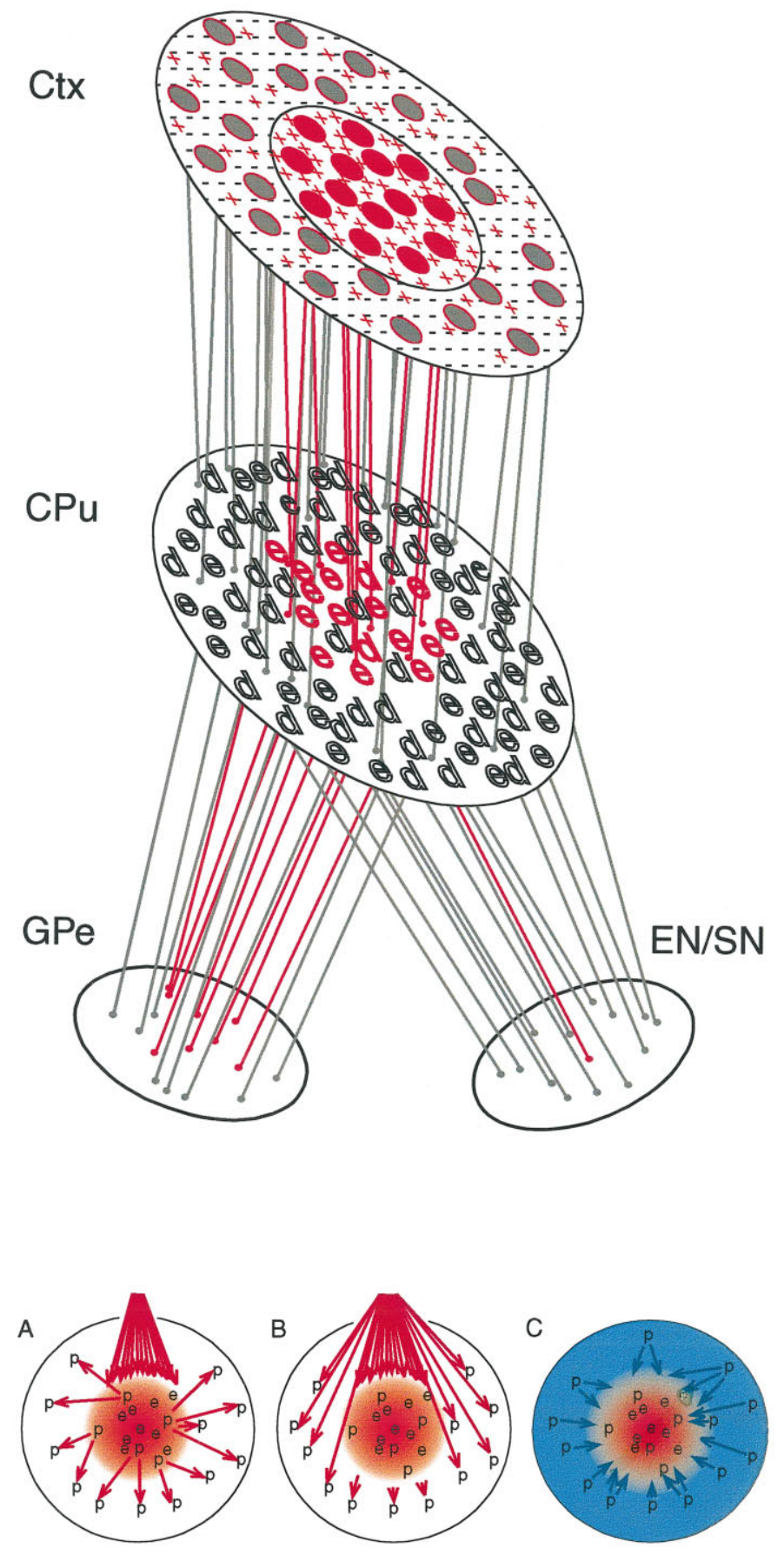

Figure 8. Top. Model of MI activation of the sensorimotor striatum. Local application of picrotoxin to MI relieves projection neurons of inhibitory control by intrinsic GABAergic interneurons. Corticostriatal neurons $(\mathrm{Ctx} ; \mathrm{red})$ become activated as a consequence and in turn stimulate a restricted population of striatal neurons $(\mathrm{CPu}$; red $)$ to express the immediate-early gene products c-Fos and JunB. Most of the activated striatal neurons are enkephalinergic $(e)$ and thus are part of the indirect basal ganglia pathway projecting to the external pallidal segment $(\mathrm{GPe})$. Dynorphin-positive projection neurons $(d)$, part of the direct pathway projecting to the internal pallidum $(E N / S N)$, show very little cortically driven induction of c-Fos and JunB after MI stimulation. Differential cortical effects on these two striatal projection neuron subtypes potentially amplify the specificity with which MI controls the indirect and direct pathways of the basal ganglia. GPe, External pallidum; $E N$, entopeduncular nucleus; $S N$, substantia nigra; $C P u$, caudoputamen; $C t x$, motor cortex. activation of intracellular cascades with the final result of gene induction (Bito et al., 1996; Liu and Graybiel, 1996; Xia et al., 1996). MK-801 also reduced gene induction in the neocortex, and it could have acted intracortically to limit excitation of corticostriatal neurons, even though it did not eliminate motor tics.

Surprisingly, blockade of AMPA receptors with GYKI 52466 did not block the cortically evoked gene induction in the striatum. The GYKI 52466 pretreatment actually increased the induction of JunB. Kita (1996) has demonstrated AMPA/kainate responses in GABAergic interneurons, which in turn elicit a GABA response in nearby projection neurons. AMPA blockade could thus increase the response of projection neurons to cortical stimulation. We were unable to test for the effects of kainate receptor blockade because of the lack of selective antagonists for use in vivo (Lerma et al., 1997), and this was true also for metabotropic glutamate receptors.

Non-NMDA receptors have been implicated in cortically induced LTD, and NMDA receptors have been implicated in LTP in the striatum (Calabresi et al., 1992). Under conditions of subthreshold depolarization, the glutamate responses of striatal projection neurons show NMDA components, which are larger and slower than the AMPA/kainate responses of these cells, favoring summation of excitatory responses (Kita, 1996). We do not claim strict parallels between these electrical events and immediate-early gene induction, but note that the differences between NMDA and non-NMDA responses in the corticostriatal system are reflected also in long-lasting events involving gene induction and protein synthesis.

\section{Differential control of the direct and indirect pathways by motor cortex}

The most striking finding in our experiments is that activation of MI differentially affects gene expression in the direct and indirect projection neurons of the striatum. Stimulation of MI activated c-Fos and JunB expression overwhelmingly (with $300 \mu \mathrm{M}$ picrotoxin) or exclusively (with $75 \mu \mathrm{M}$ picrotoxin) in enkephalincontaining indirect pathway neurons. By contrast, very few dynorphin-containing direct pathway neurons showed a gene response to motor cortex excitation (Fig. 8). In the squirrel monkey, electrical stimulation of motor or somatosensory cortex also predominantly induces c-Fos in the enkephalinergic projection neurons of the putamen (Parthasarathy and Graybiel, 1997). Our results, in a reproducible paradigm devoid of anesthesia, corroborate and substantially extend the results obtained in the primate.

The most extreme interpretation of our findings would be that MI projects almost exclusively to indirect pathway neurons rather than to direct pathway neurons. From the available anatomical evidence, we

$\leftarrow$

Figure 9. Bottom. Model of intrastriatal network activity resulting from MI stimulation. Parvalbumin-positive interneurons $(p)$ expressing c-Fos were found both inside the region of most intense induction, in which activated projection neurons were located, and in a region around this central zone. $A$ and $B$ show two different mechanisms that might account for the activation of parvalbumin-containing neurons outside the region of most intense induction. $A$, Indirect activation, possibly through the gap junction network that these striatal interneurons have been shown to form (Kita, 1990). B, Direct activation by corticostriatal fibers resulting from the high sensitivity of parvalbuminpositive neurons to cortical activation (Kita, 1990), allowing them to respond to the firing of sparsely distributed corticostriatal fibers coming from the borders of the stimulated region of MI. $C$, By either mechanism, GABAergic parvalbumin-containing interneurons activated by the cortex could induce a region of surround inhibition that could restrict and shape the central zone of most intense induction. 
do not think that complete segregation of inputs is likely (Dubé et al., 1988; Hersch et al., 1995; Kincaid and Wilson, 1996); however, differences in the innervation densities or placement of cortical inputs to the two cell types could account for the results, as could different levels of expression of glutamate receptor subtypes, $\mathrm{Ca}^{2+}$ channels, or kinase or phosphatase cascades controlling nuclear events (Malenka and Nicoll, 1993; Tallaksen-Greene and Albin, 1994; Ghosh and Greenberg, 1995; Landwehrmeyer et al., 1995; Bito et al., 1996; Liu and Graybiel, 1996; Wilson and Kawaguchi, 1996). Specialization in the intrinsic connectivity of the two cell types or in noncortical extrinsic connections could also be critical (Dubé et al., 1988; Lapper and Bolam, 1992; Kawaguchi et al., 1990; Sidibé and Smith, 1996). Particularly interesting is the report by Sidibé and Smith (1996) that thalamostriatal afferents preferentially innervate direct pathway neurons. This suggests that a cortico-thalamo-striatal activation pathway is not likely to account for the gene activation we found in enkephalinergic neurons, although differences in thalamic or other connectivity might contribute to the difference in direct and indirect neuron responsivity that we found. We emphasize that in any given experiment, on the order of $35 \%$ (c-Fos) to $50 \%$ (JunB) of the enkephalin-immunoreactive neurons in the field of induction showed immunodetectable levels of immediate-early gene induction. Conceivably, this could reflect the presence of subtypes of enkephalinergic neurons.

Such differential control by the motor cortex over indirect pathway striatal neurons is of great potential clinical interest, because many therapeutic approaches to basal ganglia disorders involve selective manipulation of the direct and indirect pathways (Chesselet and Delfs, 1996; Graybiel, 1996, and references therein). Our results and those of Parthasarathy and Graybiel (1997) provide the first evidence for a functional difference in cortical control of the direct and indirect pathways. It will be of great interest to learn whether the distributions we show here hold for inputs from other areas of cortex and for other transcriptional events.

We looked for, but did not find, different levels of immediateearly gene induction in the two segments of the globus pallidus. In the primate, however, our group has found that electrical stimulation of the primary somatosensory and motor cortex induces transneuronal c-Fos expression exclusively in the external segment of the globus pallidus, the target of indirect pathway neurons (Parthasarathy and Graybiel, 1997). Our different findings in the rat may reflect the greater arborization in the basal ganglia pathways of the rodent (Chang et al., 1981; Kawaguchi et al., 1990).

\section{Differential cortical control of striatal interneurons}

Interneurons constitute a minority of all striatal cells but can critically modulate basal ganglia function (Aosaki et al., 1995; Kawaguchi et al., 1995). We found a remarkably selective induction of c-Fos in parvalbumin-containing interneurons in and around the focus of activated projection neurons, and an even wider field of induction of NADPH diaphorase-containing interneurons, principally around rather than within the central zone of activation. These patterns of induction, taken together, suggest that the striatal response to a local excitation of MI includes (1) a local focus of c-Fos and JunB induction in which as many as $80-90 \%$ of the immediate-early gene-positive nuclei are expressed in indirect pathway neurons and parvalbumin interneurons and (2) a surrounding region in which almost no projection neurons are excited to express c-Fos, but in which many parvalbumin and somatostatin neurons are. Differences in the relative threshold excitability of the different neuronal types and activa- tion of the intrinsic networks formed by the interneurons may determine these core and surround distributions (Fig. 9).

c-Fos and JunB were induced in nearly identical patterns in enkephalin-containing neurons but not in parvalbumin-positive neurons after cortical stimulation. We do not know the source of the differential regulation in the parvalbumin-containing neurons, but our findings do demonstrate that the same pattern of cortical activity can lead to changes in gene expression that are specific for different classes of neurons. These selective responses, in turn, should have different consequences on protein synthesis because of the heteromeric combinatorial control of transactivational ability (for review, see Hughes and Dragunow, 1995).

\section{Plasticity in corticostriatal circuits}

Cortical interneurons powerfully shape cortical activity (Connors et al., 1988; Kawaguchi and Kubota, 1995), and the network formed by inhibitory interneurons is crucial to dynamic cortical processes and to the reorganization of cortical maps (e.g., Jacobs and Donoghue, 1991). The application of picrotoxin in our experiments could mimic, in part, such cortical remapping. Given the strong and functionally important connections between cortex and striatum, such stimulation could induce plastic changes in the cortex and in turn generate medium- or long-term events in the striatum by affecting protein synthesis. The patterns of cortically evoked gene expression in our experiments point to such changes as being highly differentiated according to the different neuronal populations in the affected striatum. The regulatory machinery governing the expression of c-Fos and JunB is highly responsive to cortical stimulation in striatal neurons that give rise to the indirect pathway, which decreases activation of the motor thalamus, but it is almost unresponsive in striatal neurons that give rise to the direct pathway, which inhibits the motor thalamus. By differentially affecting gene expression and protein synthesis in indirect pathway neurons, the motor cortex could selectively affect their responsivity and activity patterns and therefore induce plastic changes with repercussions on the entire circuit.

\section{REFERENCES}

Albin RL, Young AB, Penney JB (1989) The functional anatomy of basal ganglia disorders. Trends Neurosci 12:366-375.

Albin RL, Makowiec RL, Hollingsworth ZR, Dure IV LS, Penney JB, Young AB (1992) Excitatory amino acid binding sites in the basal ganglia of the rat: a quantitative autoradiographic study. Neuroscience 46:35-48.

Alexander GE, Crutcher MD (1990) Functional architecture of basal ganglia circuits: neural substrates of parallel processing. Trends Neurosci 13:266-272.

Aosaki T, Kimura M, Graybiel AM (1995) Temporal and spatial characteristics of tonically active neurons of the primate's striatum. J Neurophysiol 73:1234-11252.

Apicella P, Scarnati E, Ljungberg T, Schultz W (1992) Neuronal activity in monkey striatum related to the expectation of predictable environmental events. J Neurophysiol 68:945-960.

Bito H, Deisseroth K, Tsien RW (1996) CREB phosphorylation and dephosphorylation: a $\mathrm{Ca}^{2+}$ - and stimulus duration-dependent switch for hippocampal gene expression. Cell 87:1203-1214.

Berretta S, Robertson HA, Graybiel AM (1992) Dopamine and glutamate agonists stimulate neuron-specific expression of Fos-like protein in the striatum. J Neurophysiol 68:767-777.

Calabresi P, Pisani A, Mercuri NB, Bernardi G (1992) Long-term potentiation in the striatum is unmasked by removing the voltage-dependent magnesium block of NMDA receptor channels. Eur J Neurosci 4:929-935.

Calabresi P, Pisani A, Mercuri NB, Bernardi G (1996) The corticostriatal projection: from synaptic plasticity to dysfunctions of the basal ganglia. Trends Neurosci 19:19-24.

Chagnac-Amitai Y, Connors BW (1989a) Horizontal spread of synchronized activity in neocortex and its control by GABA-mediated inhibition. J Neurophysiol 61:747-758.

Chagnac-Amitai Y, Connors BW (1989b) Synchronized excitation and 
inhibition driven by intrinsically bursting neurons in neocortex. J Neurophysiol 62:1149-1162.

Chang HT, Wilson CJ, Kitai ST (1981) Single neostriatal efferent axons in the globus pallidus: a light and electron microscopic study. Science 213:915-918.

Chesselet M-F, Delfs JM (1996) Basal ganglia and movement disorders: an update. Trends Neurosci 19:417-422.

Collins RC, Olney JW (1982) Cortical seizures cause distant thalamic lesions. Science 218:177-179.

Connors BW (1984) Initiation of synchronized neuronal bursting in neocortex. Nature 310:685-687.

Connors BW, Malenka RC, Silva LR (1988) Two inhibitory postsynaptic potentials, and GABAa and GABAb receptor-mediated responses in neocortex of rat and cat. J Physiol (Lond) 406:443-468.

Donevan SD, Rogawski MA (1993) GYKI 52466, a 2,3-benzodiazepine, is a highly selective, non-competitive antagonist of AMPA/kainate receptors responses. Neuron 10:51-59.

Dubé L, Smith AD, Bolam JP (1988) Identification of synaptic terminals of thalamic or cortical origin in contact with distinct medium-size spiny neurons in the rat striatum. J Comp Neurol 267:455-471.

Figueredo-Cardenas G, Morello M, Sancesario G, Bernardi G, Reiner A (1996) Colocalization of somatostatin, neuropeptide $Y$, neuronal nitric oxide synthase and NADPH-diaphorase in striatal interneurons in rats. Brain Res 735:317-324.

Fonnum F, Storm-Mathisen J, Divac I (1981) Biochemical evidence for glutamate as neurotransmitter in cortical and corticothalamic fibers in the rat brain. Neuroscience 6:863-873.

Fu L, Beckstead RM (1992) Cortical stimulation induces Fos expression in striatal neurons. Neuroscience 46:329-334.

Gerfen CR (1992) The neostriatal mosaic: multiple levels of compartmental organization. Trends Neurosci 15:133-139.

Ghosh A, Greenberg ME (1995) Calcium signaling in neurons: molecular mechanisms and cellular consequences. Science 268:239-247.

Graybiel AM (1990) Neurotransmitters and neuromodulators in the basal ganglia. Trends Neurosci 13:244-254.

Graybiel AM (1995) Building action repertoires: memory and learning functions of the basal ganglia. Curr Opin Neurobiol 5:733-741.

Graybiel AM (1996) Basal ganglia: new therapeutic approaches to Parkinson's disease. Curr Biol 6:368-371.

Graybiel AM, Aosaki T, Flaherty AW, Kimura M (1994) The basal ganglia and adaptive motor control. Science 265:1826-1831.

Hersch SM, Ciliax BJ, Gutekunst CA, Rees HD, Heilman CJ, Yung KKL, Bolam JP, Ince E, Yi H, Levey AI (1995) Electron microscopic analysis of D1 and D2 dopamine receptor proteins in the dorsal striatum and their synaptic relationships with motor corticostriatal afferents. J Neurosci 15:5222-5237.

Hikosaka O, Kato Rand M, Miyachi S, Miyashita K (1995) Procedural learning in the monkey. In: Functions of the cortico-basal ganglia loop (Kimura M, Graybiel AM, eds), pp 18-30. Tokyo: Springer.

Hiroi N, Graybiel AM (1996) Atypical and typical neuroleptic treatment induce distinct programs of transcription factor expression in the striatum. 374:70-83.

Houk JC, Davis JL, Beiser DG (1995) Models of information processing in the basal ganglia. Cambridge, MA: MIT.

Hughes P, Dragunow M (1995) Induction of immediate early genes and the control of neurotransmitter-regulated gene expression within the nervous system. Pharmacol Rev 47:133-178.

Jacobs KM, Donoghue JP (1991) Reshaping the cortical motor map by unmasking latent intracortical connections. Science 251:944-947.

Kawaguchi Y, Kubota Y (1995) Local circuit neurons in the frontal cortex and the neostriatum. In: Functions of the cortico-basal ganglia loop (Kimura M, Graybiel AM, eds), pp 73-88. Tokyo: Springer.

Kawaguchi Y, Wilson CJ, Emson PC (1990) Projection subtypes of rat neostriatal matrix cells revealed by intracellular injection of biocytin. J Neurosci 10:3421-3438.

Kawaguchi Y, Wilson CJ, Augood SJ, Emson PC (1995) Striatal interneurons, chemical, physiological and morphological characterization. Trends Neurosci 18:527-535.

Kincaid AE, Wilson CJ (1996) Corticostriatal innervation of the patch and matrix in the rat neostriatum. J Comp Neurol 374:578-592.

Kita H (1990) GABAergic circuits of the striatum. Prog Brain Res 99:51-72.

Kita H (1996) Glutamatergic and GABAergic postsynaptic responses of striatal spiny neurons to intrastriatal and cortical stimulation recorded in slice preparations. Neuroscience 70:925-940.
Knowlton BJ, Mangels JA, Squire LR (1996) A neostriatal habit learning system in humans. Science 273:1399-1354.

Landwehrmeyer GB, Standaert DG, Testa CM, Penney JB, Young AB (1995) NMDA receptor subunit mRNA expression by projection neurons and interneurons in the rat striatum. J Neurosci 15:5297-5307.

Lapper SR, Bolam JP (1992) Input from the frontal cortex and the parafascicular nucleus to cholinergic interneurons in the dorsal striatum of the rat. Neuroscience 51:533-545.

Lerma J, Morales M, Vicente MA, Herreras O (1997) Glutamate receptors of the kainate type and synaptic transmission. Trends Neurosci 20:9-12.

Liu F-C, Graybiel AM (1996) Spatiotemporal dynamics of CREB phosphorylation: transient versus sustained phosphorylation in the developing striatum. Neuron 17:1133-1144.

Malenka RC, Nicoll RA (1993) NMDA-receptor-dependent synaptic plasticity: multiple forms and mechanisms. Trends Neurosci 16:521-527.

McGeorge AJ, Faull RLM (1989) The organization of the projection from the cerebral cortex to the striatum in the rat. Neuroscience 29:503-537.

Melzer P, Van der Loos H, Dorfl J, Welker E, Robert P, Emery D, Berrini J (1985) A magnetic device to stimulate selected whiskers of freely moving or restrained small rodents: its application in a deoxyglucose study. Brain Res 348:229-240.

Morgan JI, Curran T (1995) Immediate-early genes: ten years on. Trends Neurosci 18:66-67.

Neafsey EJ, Bold EL, Haas G, Hurley-Gius KM, Quirk G, Sievert CF, Terreberry RR (1986) The organization of the rat motor cortex: a microstimulation mapping study. Brain Res Rev 11:77-96.

Parthasarathy HB, Graybiel AM (1997) Cortically driven immediate-early gene expression reflects modular influence of sensorimotor cortex on identified striatal neurons in the squirrel monkey. J Neurosci 17:2477-2491.

Paxinos G, Watson C (1986) The rat brain in stereotaxic coordinates. New York: Academic.

Petralia RS, Wenthold RJ (1992) Light and electron immunocytochemical localization of AMPA-selective glutamate receptors in the rat brain. J Comp Neurol 318:329-354.

Robbins TW, Everitt BJ (1992) Functions of dopamine in the dorsal and ventral striatum. Semin Neurosci 4:119-127.

Schultz W (1995) The primate basal ganglia between the intention and the outcome of action. In: Functions of the cortico-basal ganglia loop (Kimura M, Graybiel AM, eds), pp 31-48. Tokyo: Springer.

Sheng M, Greenberg ME (1990) The regulation and function of c-fos and other immediate early genes in the nervous system. Neuron 4:477-485.

Sidibé M, Smith Y (1996) Differential synaptic innervation of striatofugal neurones projecting to the internal and external segments of the globus pallidus by thalamic afferents in the squirrel monkey. J Comp Neurol 365:445-465.

Tallaksen-Greene SJ, Albin RL (1994) Localization of AMPA-selective excitatory amino acid receptor subunits in identified populations of striatal neurons. Neuroscience 61:509-519.

Testa CM, Standaert DG, Young AB, Penney JB (1994) Metabotropic glutamate receptor mRNA expression in the basal ganglia of the rat. J Neurosci 14:3005-3018.

Thomson AM, Deuchars J (1994) Temporal and spatial properties of local circuits in neocortex. Trends Neurosci 17:119-126.

Vincent SR (1983) Histochemical demonstration of separate populations of somatostatin and cholinergic neurons in the rat striatum. Neurosci Lett 35:111-114.

Wan XST, Liang F, Moret V, Wiesendanger M, Rouiller EM (1992) Mapping of the motor pathways in rats: c-fos induction by intracortical microstimulation of the motor cortex correlated with the efferent connectivity of the site of cortical stimulation. Neuroscience 49:749-761.

Wilson CJ (1995) The contribution of cortical neurons to the firing pattern of striatal spiny neurons. In: Models of information processing in the basal ganglia (Houks JC, Davis JL, Beiser DG, eds), pp 29-50. Cambridge, MA: MIT.

Wilson CJ, Kawaguchi Y (1996) The origins of two-state spontaneous membrane potential fluctuations of neostriatal spiny neurons. J Neurosci 16:2397-2410.

Wong EH, Kemp JA, Priestley T, Knight AR, Woodruff GN, Iversen LL (1986) The anticonvulsant MK-801 is a potent $N$-methyl-D-aspartate antagonist. Proc Natl Acad Sci USA 83:7104-7108.

Xia Z, Dudek H, Miranti CK, Greenberg ME (1996) Calcium influx via the NMDA receptor induces immediate early gene transcription by a MAP kinase/ERK-dependent mechanism. J Neurosci 16:5425-5436. 